\title{
Optimization of mouse embryo culture media using simplex methods
}

\author{
J. A. Lawitts and J. D. Biggers \\ Laboratory of Human Reproduction and Reproductive Biology, Harvard Medical School, \\ 45 Shattuck St, Boston, MA 02115, USA
}

\begin{abstract}
Summary. Culture media were developed for pronuclear-stage mouse embryos using simplex optimization, which has the benefit of being able to optimize several components simultaneously. Initially, several different media were generated. All media contained the same components, yet each medium was characterized by having a different component at a high concentration. The simplex procedure identified 4 components ( $\mathrm{NaCl}$, pyruvate, $\mathrm{KH}_{2} \mathrm{PO}_{4}$ and glucose) which at high concentrations were detrimental to embryo development, compared to the other components tested. For example, all embryos cultured in a medium with high $\mathrm{NaCl}$ blocked at the 2-cell stage. The optimization method then adjusted each medium by lowering the concentration of the component or removing it entirely, which resulted in a significant increase in development. In an experiment comparing 8 media generated from the simplex optimization, along with 7 other media, removal of $\mathrm{KH}_{2} \mathrm{PO}_{4}$ resulted in the largest increase in development; $88 \%$ of embryos were $\geq 4$ cells on Day 3 after hCG, and $53 \%$ developed into blastocysts by Day 5 .

Another experiment compared 4 of the best media generated from the simplex optimization. In 3 out of the 4 media, $90 \%$ or more of the embryos were $\geq 4$ cells on Day 3. In 3 of the media, approximately $60 \%$ or more of the embryos developed into blastocysts. The simplex optimization procedure is an efficient method for developing culture media and determining requirements for development in vitro.
\end{abstract}

Keywords: Simplex; culture; mouse; embryo

\section{Introduction}

An efficient method for optimizing culture media is one that would optimize a large number of variables simultaneously. If a medium contains $n$ components, then the responses to all possible mixtures of these components can be represented by a concentration response surface in $(n+1)$ dimensional space (Biggers et al., 1957, 1971). Our objective is to find on this surface the mixture which gives the optimum, usually the maximal, response. The classical experimental procedure of studying the effects of varying the concentration of each component, one at a time, is inefficient and has the defect of being unable to detect the interactions that occur between the different components. Alternative methods for exploring concentration response surfaces, which investigate interactions, are factorial experimental designs and group-rotatable designs. Brinster (1965a) used a $3 \times 3$ factorial design to examine the effect of different combinations of lactate and pyruvate. However, both factorial and group-rotatable designs have limited use in practice when several components are involved since large numbers of media would have to be made up and compared. A factorial experiment designed to investigate the effects of 10 components each at two concentrations would require the comparison of 1024 media (see Cox, 1958, for a theoretical discussion). 
An alternative approach to locating the highest point of a concentration response surface is simplex optimization (Spendley et al., 1962). This technique requires much smaller numbers of experimental points. The original simplex method has been modified by Routh et al. (1977) and van der Wiel (1980) and is called super modified simplex. Two computer programs are now commercially available to control the experimental program-COPS from Elsevier Scientific Software, New York, USA, and SIMPLEX-V $\mathrm{M}$ from Statistical Programs, Houston, Texas, USA. We have adapted the COPS program to optimize 10 components in a medium for the culture of mouse preimplantation embryos. Our method takes into consideration the biological variation associated with culture systems.

The development in vitro of 1-cell zygotes into blastocysts was first reported by Whitten \& Biggers (1968), using F1, C57BL/10J $\times \mathrm{SJL} / \mathrm{J}$ females as zygote donors. Zygotes from randombred strains of mice usually divide into 2 cells and arrest. This phenomenon, originally described by Cole \& Paul (1965), came to be known as the 2-cell block, and it has been overcome by growing 2-cell embryos in explanted oviducts (Whittingham \& Biggers, 1967), or by injecting cytoplasm from a non-blocking strain of embryo into a blocking strain (Muggleton-Harris et al., 1982; Muggleton-Harris \& Brown, 1988). There have been reports of the development in vitro of 1-cell zygotes to the blastocyst stage from certain random-bred strains of mice, utilizing already existing media (Loutradis et al., 1987; Dandekar \& Glass, 1987), or modifications of existing media (Pomp et al., 1988; Chatot et al., 1989, 1990; Spindle, 1990). Clearly, it would be beneficial to have an efficient sequential method to determine requirements for the in-vitro development of zygotes from blocking mouse strains such as CF1 or CD1. Simplex optimization is that method and we have used this method to culture pronuclear stage mouse embryos into blastocysts while optimizing a large number of variables in the medium simultaneously.

\title{
Materials and Methods
}

\begin{abstract}
Animals. Random bred female mice (Crl:CF1 BR, 6-8 weeks old) and hybrid male mice (B6D2F1/CrlBR) were maintained in $14 \mathrm{~h}$ light and $10 \mathrm{~h}$ dark (lights on at $05: 00 \mathrm{~h}$ ). Female mice were superovulated by intraperitoneal (i.p.) injection of 5 i.u. pregnant mares' serum gonadotrophin (PMSG; Sigma, St Louis, MO, USA) at 15:30 h, followed by an i.p. injection of human chorionic gonadotrophin (hCG; Sigma) $47 \mathrm{~h}$ later. After hCG injection, females were placed in cages with males and examined the following morning (Day 1) for the presence of a vaginal plug.
\end{abstract}

Preparation of culture media. Media were prepared from individual stock solutions of each component. All components were purchased from Sigma. Most of the components were stored in $0.1 \mathrm{M}$ solutions, with the following exceptions. $\mathrm{NaCl}$ and $\mathrm{NaHCO}_{3}$ were stored at $1.0 \mathrm{M}$, whereas bovine serum albumin (BSA; fraction $\mathrm{V}$ ) was stored at a concentration of $100 \mathrm{mg} / \mathrm{ml}, \mathrm{CaCl}_{2}$ at $0.171 \mathrm{M}$, EDTA at $1.0 \mathrm{~mm}$ and penicillin-G and streptomycin sulphate were stored as one solution at concentrations of $10000 \mathrm{units} / \mathrm{ml}$ and $5.0 \mathrm{mg} / \mathrm{ml}$, respectively. All components were stored at $4^{\circ} \mathrm{C}$, in 50-ml conical centrifuge tubes (Nunc, Denmark) except for the glutamine stock and the antibiotic mixture, which were stored at $-15^{\circ} \mathrm{C}$ in $5 \mathrm{ml}$ polypropylene tubes (Falcon No. 2063, Lincoln Park, NJ, USA). Fresh solutions of $\mathrm{NaHCO}_{3}$ and sodium pyruvate were prepared every 2 weeks (Hogan et al., 1986). Furthermore, the results were more consistent if sodium lactate was prepared every 2 weeks and BSA was prepared weekly.

On the day before the start of each trial, $10 \mathrm{ml}$ of each medium were prepared. First, the 10 components being tested (Table 1) were distributed to culture tubes (Falcon No. 2051). $\mathrm{NaHCO}_{3}$ and the antibiotic mixture were then added to each tube. Distilled $\mathrm{H}_{2} \mathrm{O}$ was added to bring the volume of each tube to $9.0-9.5 \mathrm{ml}$, and then equal amounts of $\mathrm{CaCl}_{2}$ were added. Finally, distilled $\mathrm{H}_{2} \mathrm{O}$ was added to bring the final volume of each medium to $10 \mathrm{ml}$. Each tube was inverted twice to mix the components and then the contents were drawn into a disposable syringe (BecktonDickinson, Lincoln Park, NJ, USA) and the medium was pushed through a $0 \cdot 2 \mu \mathrm{m}$ filter (Millipore) into a second tube.

Embryo collection. Mice were killed between 15:30 and 15:45 h on Day 1. Pronuclear-stage zygotes were flushed from each oviduct with $0 \cdot 1 \mathrm{ml}$ Dulbecco's phosphate buffered saline (dPBS). Pooled zygotes from several donors were washed through one drop of dPBS containing $0.65 \mathrm{mg}$ hyaluronidase $/ \mathrm{ml}$ (Sigma) to remove any cumulus cells, followed by two drops of dPBS.

Embryo culture. Zygotes were cultured in tissue-culture dishes (Costar No. 3060, Cambridge, MA, USA) in $50 \mu \mathrm{l}$-drops of medium under $5 \mathrm{ml}$ silicone oil ( 50 centistokes; Sigma). The dishes were made up the day before the start of each trial and were equilibrated overnight in an atmosphere of $6 \% \mathrm{CO}_{2}, 5 \% \mathrm{O}_{2}$ and $89 \% \mathrm{~N}_{2}$ in a plastic culture chamber (Billups-Rothenberg, Del Mar, CA, USA) inside a $37^{\circ} \mathrm{C}$ incubator. Each culture dish contained 
4 drops, and 24 zygotes were transferred from dPBS into one of the drops of culture medium. Any remaining dPBS in the transfer pipette was expelled and the pipette was refilled from another drop of culture medium. All zygotes were then transferred into the second drop: 12 zygotes were transferred from drop 2 to drop 3 , and the remaining 12 zygotes were transferred into drop 4 . The culture dishes containing the zygotes were returned to the culture chamber at $37^{\circ} \mathrm{C}$, which was gas equilibrated and then sealed. Developmental progress was recorded, as described below, at 24-h intervals. When the culture dishes were outside the culture chamber and not on the microscope stage, they were maintained at $37^{\circ} \mathrm{C}$ in a bench-top incubator (Baxter, Bedford, MA, USA).

Statistical methods. In the ongoing simplex optimization procedure, an arbitrary scoring system was used to assess developmental progress. A score of 1 was given to an embryo if development was $\geq 4$ cells on Day 3 after hCG, and a score of 4 was given to each embryo which developed to the blastocyst stage by Day 5 . The media that formed a simplex (see 'Results') were ranked according to the mean scores of all embryos tested in each medium. The worst medium was the one having the lowest score.

In the experiments reported in this paper, selected media were compared using a randomized block design with replication within each cell. The responses to the media were assessed as the proportion of embryos that were $\geq 4$ cells on Day 3 after hCG, and the proportion that reached the blastocyst stage on Day 5 . The experiments were analysed by analysis of variance after transformation of the data by a two-term inverse sine transformation, proposed by Laubscher (1961), given by:

$$
\mathrm{t}_{4}=n^{1 / 2} \sin ^{-1}(x / n)^{1 / 2}+(n+1)^{1 / 2} \sin ^{-1}[(x+3 / 4) /(n+3 / 2)]^{1 / 2},
$$

where $x=$ the number of responders, and $n=$ the group size.

The advantage of this transformation over the commonly used angular transformation is that it is more stable for proportions $<0.1$ and $>0.9$. The theoretical variance of this distribution approaches 1 as $n$ increases. A computer program was written in QuickBasic to perform these calculations. The mean transformed responses were compared using Duncan's multiple range and $t$ tests of significance (Number Cruncher Statistical System, J. L. Hintze, Kaysville, UT, USA).

\section{Results}

\section{Generation of media by simplex optimization}

A simplex is a geometrical figure with $(n+1)$ vertices, the $n$ co-ordinates defining the location of each vertex in $n$-dimensional space. A set of $(n+1)$ media can be represented by the vertices of a simplex; the co-ordinates of each vertex correspond to the concentration of the $n$ components in each medium being tested. Thus, an experiment designed to test 2 components results in a triangle which has 3 vertices and defines 3 different media, and an experiment testing 3 components results in a tetrahedron with 4 vertices that defines 4 different media. The simplex optimization procedure first defines a START simplex, in this application a set of media. The medium that gives the worst response is identified experimentally. The composition of a new medium, which should be closer to the maximum of the concentration response surface, is the geometric reflection of the co-ordinates of the worst medium of the simplex through the centroid, which is calculated from the co-ordinates of the remaining media (Fig. 1). This procedure is repeated sequentially until the optimum has been reached (van der Wiel et al., 1983).

The 10 components shown in Table 1 were selected for optimization, and so $n=10$. Eight of these components are present in M16 (Whittingham, 1971). Glutamine and EDTA were also included, based on results reported by Chatot et al. (1989). A concentration was chosen for each component to define an initial medium from which 10 other media were generated. The selected concentrations in the GENERATING medium (GENMED) were similar to those found in M16, with the following exceptions. Glucose, sodium lactate and $\mathrm{NaCl}$ were at lower concentrations than in M16, based on preliminary observations from our laboratory (J. Lawitts \& S. Palmieri, unpublished data). Glutamine was included at a concentration similar to that found in CZB, whereas EDTA was included at a concentration of $10 \mu \mathrm{M}$ (Dr Ann Kiessling, personal communication). The START simplex was computed from the GENMED medium by the COPS program according to the methods described by Spendley et al. (1962). The selected upper and lower concentrations and ranges used in these calculations are shown in Table 1. The START simplex consisted of 11 media whose compositions are shown in Table 2 . In each of the 10 media, other than the GENMED medium, 1 of the components was raised to a relatively high concentration, while 


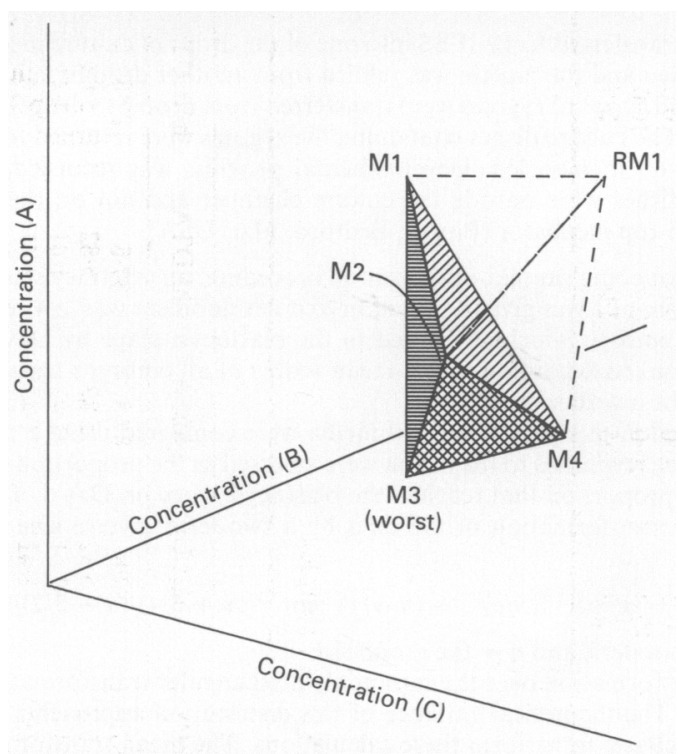

Fig. 1. A theoretical simplex optimizing 3 components: A, B and C. The START simplex consists of the pyramid with vertices M1, M2, M3 and M4. The co-ordinates of each vertex define a medium with a given concentration of components $\mathrm{A}, \mathrm{B}$ and $\mathrm{C}$. If the media were tested and Medium M3 was determined to have the worst response, a geometrical reflection would be computed to generate Medium RM1, and also a new simplex, with vertices M1, M2, M4 and RM1.

the concentrations of the remaining components were slightly raised. Embryos were cultured in each medium and the responses to each medium were entered into the COPS program. The medium which gave the worst response was determined, and a new medium was generated according to standard simplex calculations (Spendley et al., 1962). The resulting medium, which contained adjusted concentrations of all components, was tested, and another new medium was generated according to the super modified simplex procedure which is also in the COPS program (Routh et al., 1977; van der Wiel, 1980). The response of this medium was also measured, and of the two new media, the one with the better response was chosen to replace the medium with the worst response. This sequence of tests, which completes the first cycle, is illustrated using two components in Fig. 2. In each additional cycle, two more new media were produced and tested. Once again, the medium with the better response was chosen to replace the medium with the worst response.

\section{Tested media}

The first 4 cycles of the optimization procedure identified 4 components $(\mathrm{NaCl}$, pyruvate, $\mathrm{KH}_{2} \mathrm{PO}_{4}$ and glucose) which at high concentration were detrimental to embryo development, compared to the other 6 components. The media from the START simplex which contained high levels of these components ( $\mathrm{hNaCl}, \mathrm{hPYR}, \mathrm{hKH}_{2} \mathrm{PO}_{4}, \mathrm{hGLUC}$; Table 2$)$ gave the worst responses. Furthermore, during each cycle a medium was generated which had a lower amount of the component which had been detrimental at high concentration. These were the corresponding adjusted media (aNaCl, aPYR, $\mathrm{aKH}_{2} \mathrm{PO}_{4}$, aGLUC) which gave improved responses. These 8 media, the simplex-derived media shown in Table 3, were tested and compared with 5 control media and 2 reference media.

From Table 3, it is evident that every component in each adjusted medium is at a different concentration. Therefore, 5 control media were also tested (CONT, cNaCL, cPYR, $\mathrm{cKH}_{2} \mathrm{PO}_{4}$, cGLUC). The concentrations of components in the CONT medium were similar to those in the 


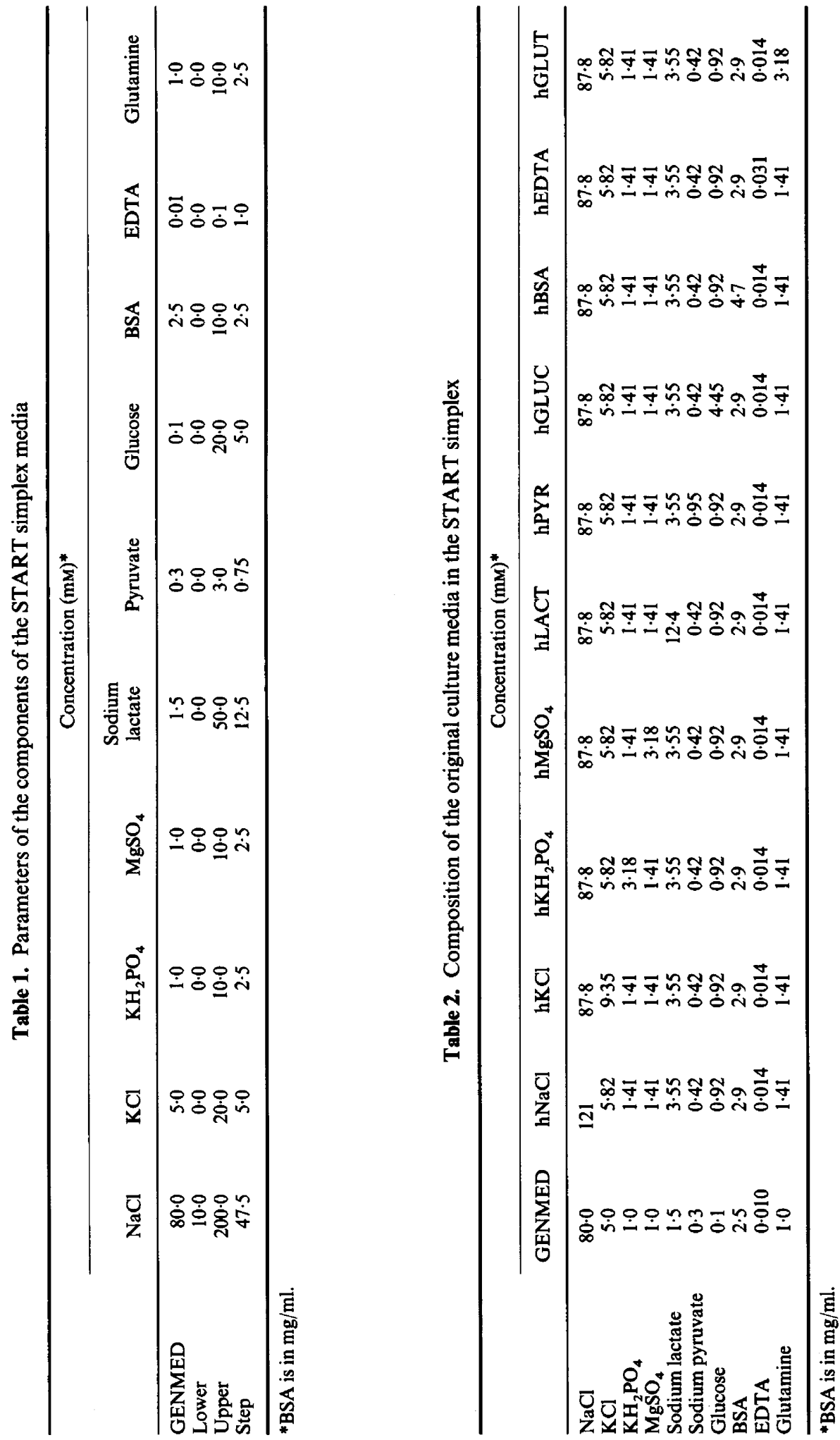




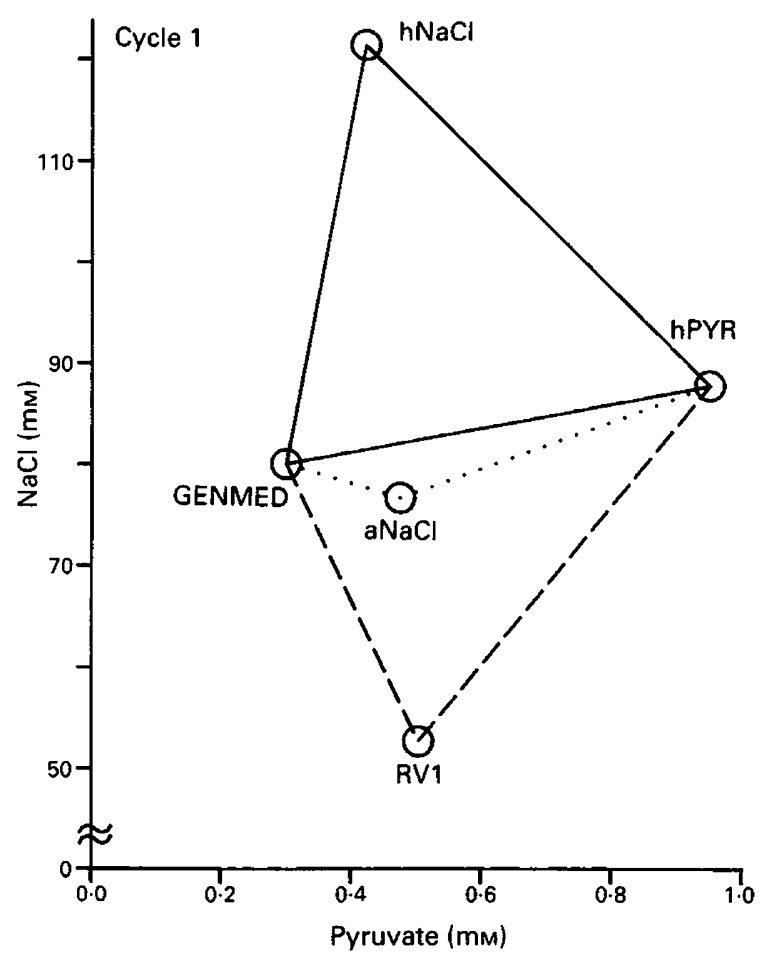

Fig. 2. The first cycle of the simplex optimization, graphing only the concentrations of 2 components, $\mathrm{NaCl}$ and pyruvate, rather than all 10 components. In the START simplex (solid line), the concentrations of $\mathrm{NaCl}$ and pyruvate are plotted for the GENERATING medium, the high $\mathrm{NaCl}$ medium and the high pyruvate medium (Table 2). This forms a triangle with vertices GENMED, $\mathrm{hNaCl}$ and $\mathrm{hPYR}$. Embryos were cultured in each medium, and the results were entered into the COPS program. Medium $\mathrm{hNaCl}$ gave the worst results, and a geometrical reflection occurred according to standard simplex calculations, to produce Medium RV1 (reflected vertex 1) and a new simplex with vertices START, hPYR and RVl (broken line). Medium RV1 was also tested and the results were entered into the COPS program. Calculations were made according to super modified simplex procedures and Medium aNaCl was generated and then tested. A higher percentage of zygotes grew from $\mathrm{aNaCl}$, than from $\mathrm{RV} 1$ or $\mathrm{hNaCl}$. Therefore, $\mathrm{aNaCl}$ replaced $\mathrm{hNaCl}$ and $\mathrm{RV} 1$, resulting in a new simplex with vertices GENMED, hPYR and aNaCl (dotted line). This completes the first cycle.

START simplex media, except that no single component in CONT was raised to a high level. In the other 4 control media, the concentrations of components were also similar to those in their corresponding START simplex media, except that the component that the control medium was named for was at an adjusted level instead of a high level. The responses of zygotes in these 13 media were also compared with those in 2 reference media: M16 and CZB. M16 is a commonly used culture medium, which will support the development of 2-cell embryos, yet causes a 2-cell block in mouse embryos from random-bred strains (Whittingham, 1971). CZB is a modification of BMOC2 (Ebert \& Brinster, 1983), which contains glutamine and no glucose. A high proportion of CF1 zygotes developed into morulae in this medium, and additional glucose on Day 3 of culture promoted development to the blastocyst stage (Chatot et al., 1989). We tested Medium CZB without adding glucose on Day 3.

The responses to the 15 media were compared simultaneously in 6 trials, using a randomized block design with replication within each cell. Therefore, in each block two groups of 12 zygotes were cultured in each medium. The results are summarized in Figs 3 and 4. A wide range of 
空

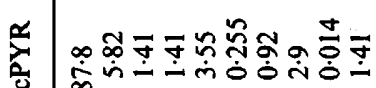

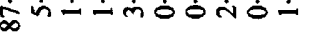

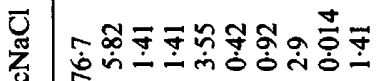
乬

ํํㄹ m

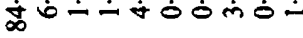

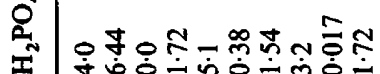

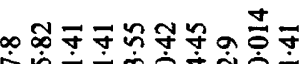

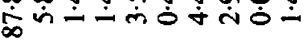

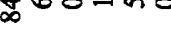

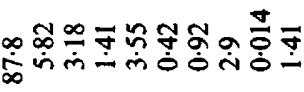

m $\infty$ 旁

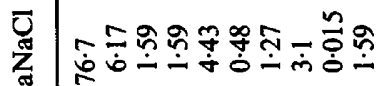

Z

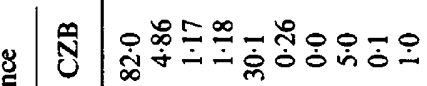


responses occurred and resulted in several groups of media for which the within-group responses were not significantly different. Several of the media supported the development of a high percentage of embryos beyond the 2-cell stage, demonstrating that the embryos will develop in media with widely different compositions. Of the simplex-derived media, $\mathrm{aKH}_{2} \mathrm{PO}_{4}$ gave the largest responses; $88 \%$ of embryos were $\geq 4$ cells by Day 3 and $53 \%$ became blastocysts. These responses are not significantly different from those in Medium CZB, in which $83 \%$ of the embryos were $\geq 4$ cells and $60 \%$ became blastocysts without addition of glucose. Of the simplex-derived media, $\mathrm{hNaCl}$ gave the worst response; all embryos failed to develop beyond the 2-cell stage. The response in this medium was similar to that obtained with $\mathrm{M} 16$. When the concentration of $\mathrm{NaCl}$ was reduced from $121 \mathrm{~mm}(\mathrm{hNaCl}$; Table 3) to $87.8 \mathrm{~mm}$ (CONT), a proportion of embryos (38\%) developed to $\geq 4$ cells and $12 \%$ reached the blastocyst stage. Relative to the CONT medium, Duncan's multiple range test showed that increasing the concentration of pyruvate (hPYR) or $\mathrm{KH}_{2} \mathrm{PO}_{4}\left(\mathrm{hKH}_{2} \mathrm{PO}_{4}\right)$ inhibited the development of embryos at the 2-cell stage. In contrast, there was no decrease in development when glucose concentration was raised from $0.92 \mathrm{~mm}$ (CONT) to $4.45 \mathrm{~mm}$ (hGLUC). When embryos were cultured in Media $\mathrm{cNaCl}$, $\mathrm{cPYR}$ or cGLUC, development was not significantly different from that in the corresponding adjusted media ( $\mathrm{aNaCl}, \mathrm{aPYR}$ and aGLUC), which suggests that the observed improvement in development in each case was primarily due to the modification of one component. However, a significantly higher percentage of embryos were $\geq 4$ celled during culture in Medium aKH $\mathrm{PO}_{4}$, compared with $\mathrm{cKH}_{2} \mathrm{PO}_{4}$.

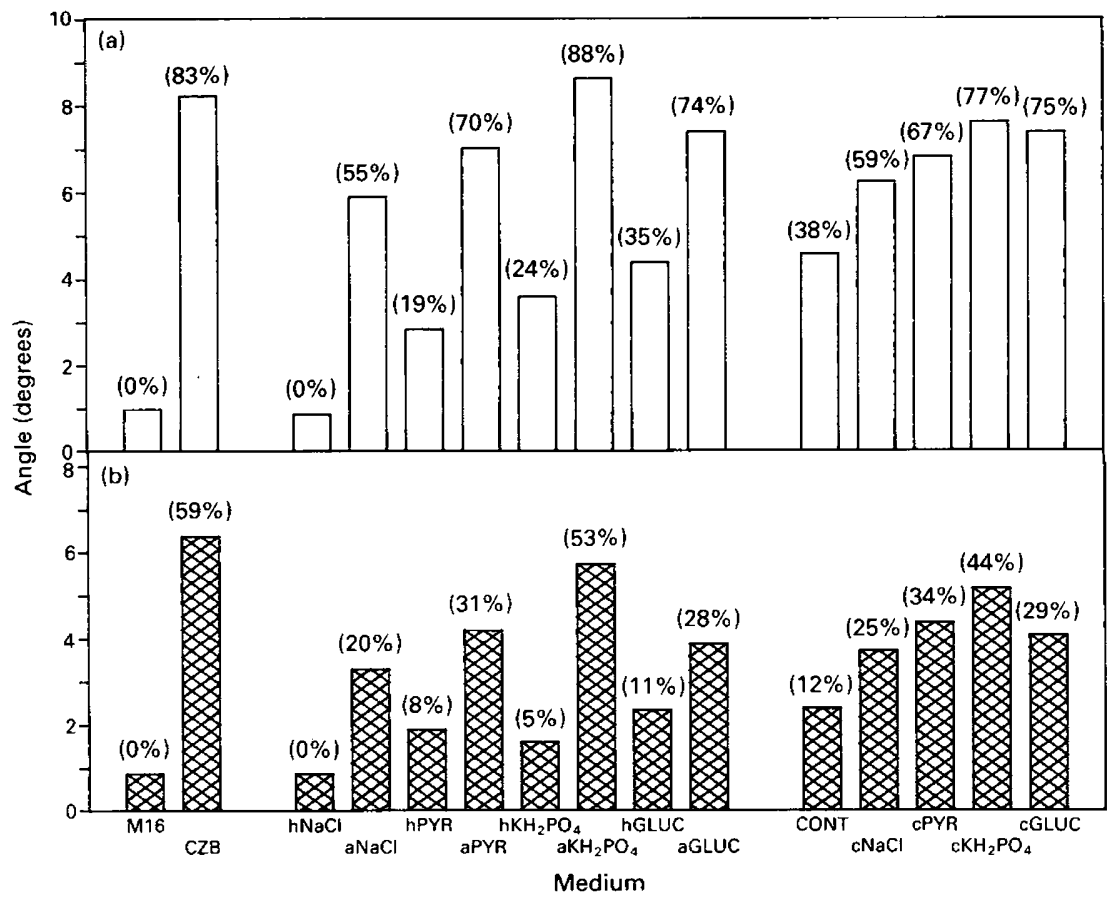

Fig. 3. The mean transformed percentage of zygotes that developed to (a) $\geq 4$ cells and (b) blastocysts in the 15 media shown in Table 3. The mean percentage response is shown above each bar. The standard error (s.e.) difference of two means $(\mathrm{d} . f .=70)=0.53$ (the error term is derived from the blocks $\times$ media interaction).

The experiment just described involved testing 15 media at one time. A consequence of the labour involved was that it took approximately $1 \mathrm{~h}$ to collect embryos from 15 mice and then wash them in dPBS. It took an additional hour to transfer 24 embryos into each culture dish. By the 

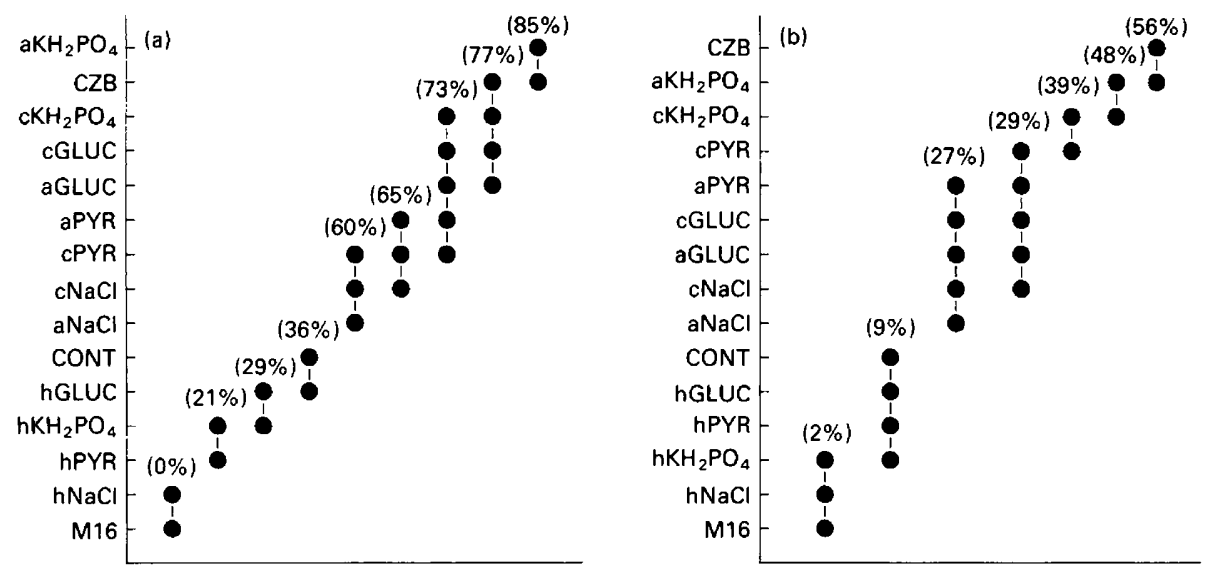

Fig. 4. The development of zygotes to (a) $\geq 4$ cells and (b) blastocysts in the media shown in Fig. 3, grouped according to results from Duncan's multiple range test. Points connected by lines represent media which are not significantly different $(P>0.05)$. Numbers in parentheses represent the mean percentage development for that group of media.

time all embryos were transferred into culture medium, the osmolarity of the dPBS in which the embryos were stored approached 1000 mosmol. Since the large experiment could have created stress conditions, the 4 adjusted media and CZB were compared under more optimal conditions by using fewer treatment groups. Embryos were flushed from 7-9 mice and were placed in culture within $1 \mathrm{~h}$ after the start of the procedure, compared to $2 \mathrm{~h}$ in the larger experiment.

When embryos were cultured under these presumably more optimal conditions, in 3 out of the 5 media tested (CZB, aPYR and $\left.\mathrm{aKH}_{2} \mathrm{PO}_{4}\right) 90 \%$ or more of the embryos were $\geq 4$ cells by Day 3 (Fig. 5a). Furthermore, in 4 out of the 5 media tested (CZB, aPYR, aKH ${ }_{2} \mathrm{PO}_{4}$ and aGLUC), approximately $60 \%$ or more of the embryos developed into blastocysts (Fig. $5 \mathrm{~b}$ ). A $t$-test comparison showed that the responses for blastocyst development in Media $\mathrm{aKH}_{2} \mathrm{PO}_{4}$ and $\mathrm{CZB}$ were not significantly different, in agreement with the results of the first experiment.

\section{Discussion}

Whether the use of simplex optimization results in a better medium depends on several factors, one being the topography of the concentration response surface (Fig. 6). If the undulations of the response surface are of similar magnitude to the background variation (noise) there will be little, if any, progress made. This situation could be the case for Simplex I (Fig. 6), located in a region where the contours of similar response are far apart. The fact that we made rapid improvements in the medium with respect to 4 components $\left(\mathrm{NaCl}\right.$, pyruvate, $\mathrm{KH}_{2} \mathrm{PO}_{4}$ and glucose) indicates that we located the START simplex in a region of the concentration response surface where a large change in response resulted from a change in concentrations of these components (see Simplexes II and III in Fig. 6). There is also the possibility that multiple local optima exist on the concentration response surface (Fig. 6), and that the optimum which is reached depends on the location of the START simplex. The finding that the development of zygotes to blastocysts in Media CZB and $\mathrm{aKH}_{2} \mathrm{PO}_{4}$ is not significantly different suggests that multiple local optima do indeed exist. There are other topographies which may interfere with the approach to the overall optimum (Deming \& Morgan, 1973). If these are encountered it will be necessary to begin the optimization sequence again using a new START simplex.

The simplex optimization procedure does not select the compounds whose concentrations are to be varied. The selection process must depend on biological information. A strength of the 


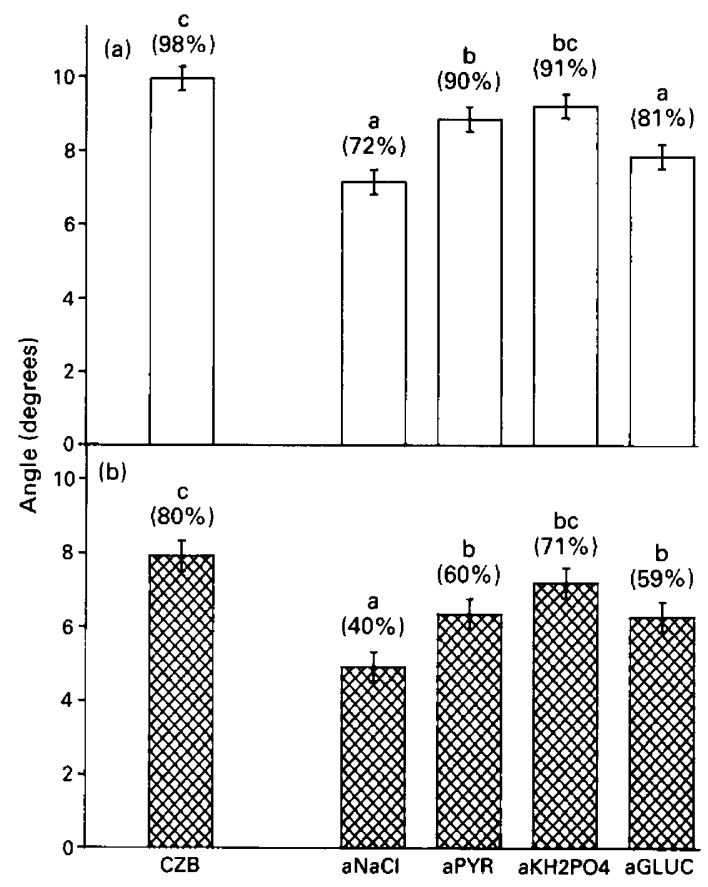

Fig. 5. The development of zygotes (a) to $\geq 4$ cells and (b) into blastocysts after they were cultured in only 5 media instead of 15 . Letters $(a, b, c)$ above the bars are from Duncan's multiple range test. Media labelled with different letters are significantly different $(P<0.05)$.

simplex optimization method, however, is that it causes media to be tested that have compositions which may be considered extreme, according to previous information. The benefit from testing these media is that they create unexpected physiological questions. In our work the media which have been tested have focussed our attention on such questions as the effect of high $\mathrm{Na}^{+}$or $\mathrm{Cl}^{-}$ concentration, low $\mathbf{P}_{\mathrm{i}}$ concentration and osmolarity.

A surprising result was that Medium $\mathrm{hNaCl}$ completely blocked embryo development at the 2-cell stage. This block should not have been due to high osmolarity ( $285 \mathrm{mosmol}$; Table 4$)$, a value close to the optimum according to Brinster (1965b). It is more likely that high concentrations of either $\mathrm{Na}^{+}$or $\mathrm{Cl}^{-}$ions are blocking embryo development. There is evidence to suggest that decreasing $\mathrm{Na}^{+}$concentration increased in-vitro development (Pomp et al., 1988). In the present experiment, $\mathrm{Cl}^{-}$concentration in Medium $\mathrm{hNaCl}(130 \mathrm{mM})$ was $45 \%$ and $39 \%$ higher than in CZB $(90.3 \mathrm{mM})$ and $\mathrm{aKH}_{2} \mathrm{PO}_{4}(93.8 \mathrm{mM})$, respectively; whereas $\mathrm{Na}^{+}$concentration in Medium $\mathrm{hNaCl}$ $(150 \mathrm{~mm})$ was $9 \%$ and $31 \%$ higher than in CZB (137 mM) and $\mathrm{aKH}_{2} \mathrm{PO}_{4}(114 \mathrm{~mm})$, respectively. Therefore, it is possible the the $\mathrm{Cl}^{-}$concentration is responsible for the block at the 2-cell stage caused by the $\mathrm{hNaCl}$ medium. Although there is no prior evidence for a direct effect $\mathrm{Cf}^{-}$on embryos, it has been shown that both the $\mathrm{Na}^{+} / \mathrm{H}^{+}$antiport (Baltz et al., 1990) and the $\mathrm{Na}^{+}$dependent $\mathrm{Cl}^{-} / \mathrm{HCO}_{3}{ }^{-}$antiport (Baltz et al., 1991), which regulate acid load in a number of cell types, is absent in the mouse 2-cell embryo. However, a $\mathrm{Na}^{+}$-independent $\mathrm{Cl}^{-} / \mathrm{HCO}_{3}{ }^{-}$antiport, which regulates alkaline loads, is present in these cells and a high external concentration of $\mathrm{Cl}^{-}$ would tend to lower the $\mathrm{pH}_{\mathrm{i}}$ of the blastomeres via the antiport. If the $\mathrm{pH}_{\mathrm{i}}$ falls sufficiently, a block to development could occur. Modification of media by adjusting the sodium pyruvate or sodium lactate concentrations usually involves adjustment of $\mathrm{NaCl}$ levels to maintain osmolarity (Brinster, 1965a, b; Cross \& Brinster, 1973; Gardner et al., 1989). Our data indicate that this practice may be detrimental to embryo development. 


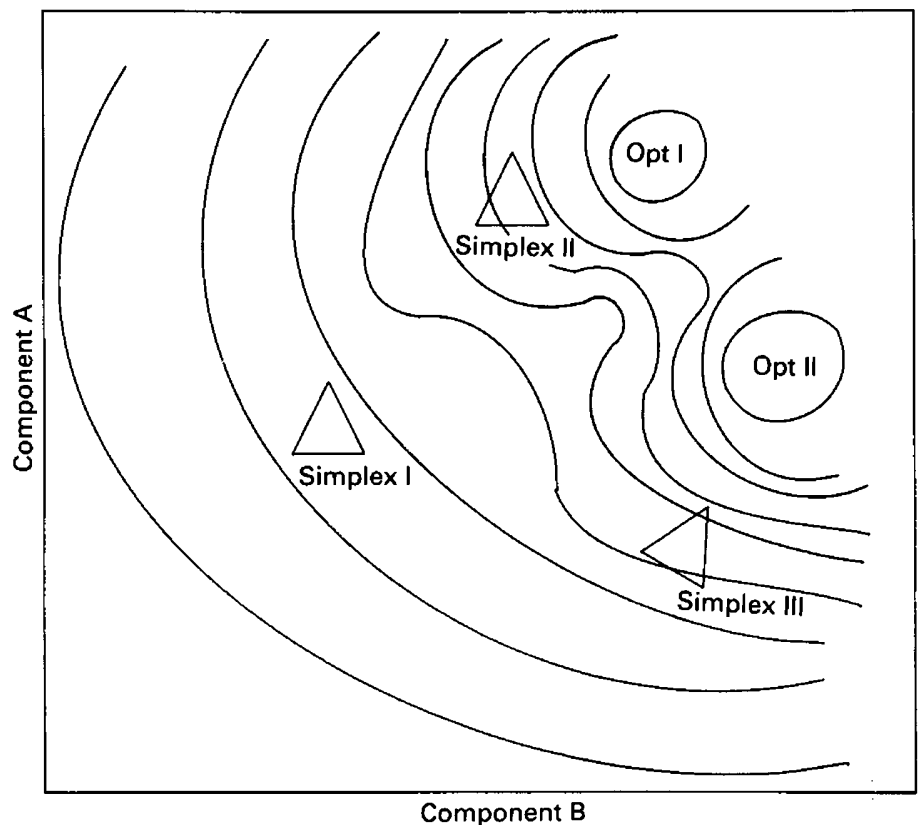

Fig. 6. Theoretical response surface with two different optima. Simplex I is started in an area of the surface where the contours of similar response are far apart. Little progress, if any, will be made. Simplex II and Simplex III are started in an area of the response surface where the contours are closer together, resulting in a rapid ascent toward the optimum, compared to Simplex I.

Table 4. Components, lactate/pyruvate ratio, observed $\mathrm{pH}$ and osmolarity, \pm s.e., of culture media

\begin{tabular}{|c|c|c|c|c|c|c|c|}
\hline \multirow[b]{2}{*}{ Medium } & \multicolumn{4}{|c|}{ Components (mM) } & \multirow{2}{*}{$\begin{array}{l}\text { Lactate/ } \\
\text { pyruvate }\end{array}$} & \multirow{2}{*}{$\begin{array}{c}\mathrm{pH} \\
(N=4)\end{array}$} & \multirow{2}{*}{$\begin{array}{c}\text { Osmolarity } \\
\text { (mosmol) } \\
(N=6)\end{array}$} \\
\hline & $\mathrm{Na}^{+}$ & $\mathrm{Cl}^{-}$ & $\mathbf{K}^{+}$ & $\mathrm{PO}_{4}^{-}$ & & & \\
\hline $\begin{array}{l}\text { M16 } \\
\text { CZB }\end{array}$ & $\begin{array}{l}143 \\
137\end{array}$ & $\begin{array}{l}103 \\
90 \cdot 3\end{array}$ & $\begin{array}{l}5.97 \\
6.03\end{array}$ & $\begin{array}{l}1 \cdot 19 \\
1 \cdot 17\end{array}$ & $\begin{array}{l}70 \cdot 5 \\
116\end{array}$ & $\begin{array}{l}7.5 \pm 0.04 \\
7.5 \pm 0.00\end{array}$ & $\begin{array}{l}271 \pm 1.95 \\
259 \pm 1.17\end{array}$ \\
\hline $\begin{array}{l}\text { hNaCl } \\
\text { aNaCl } \\
\text { hPYR } \\
\text { aPYR } \\
\text { hKH }_{2} P_{4} \text { PO }_{4} \\
\text { aKH }_{2} \mathrm{PO}_{4} \\
\text { hGLUC } \\
\text { aGLUC }\end{array}$ & $\begin{array}{l}150 \\
107 \\
117 \\
115 \\
117 \\
114 \\
116 \\
114\end{array}$ & $\begin{array}{l}130 \\
86.3 \\
97 \cdot 0 \\
94.9 \\
97.0 \\
93.8 \\
97.0 \\
94.1\end{array}$ & $\begin{array}{l}7.23 \\
7.76 \\
7.23 \\
7.83 \\
9.0 \\
6.44 \\
7.23 \\
7.59\end{array}$ & $\begin{array}{l}1.41 \\
1.59 \\
1.41 \\
1.61 \\
3.18 \\
- \\
1.41 \\
1.21\end{array}$ & $\begin{array}{c}8 \cdot 39 \\
9 \cdot 30 \\
3 \cdot 72 \\
17 \cdot 8 \\
8 \cdot 39 \\
13 \cdot 4 \\
8 \cdot 39 \\
13 \cdot 0\end{array}$ & $\begin{array}{l}7.4 \pm 0.01 \\
7.5 \pm 0.01 \\
7.5 \pm 0.03 \\
7.5 \pm 0.00 \\
7.4 \pm 0.02 \\
7.5 \pm 0.00 \\
7.5 \pm 0.01 \\
7.5 \pm 0.00\end{array}$ & $\begin{array}{l}285 \pm 1.82 \\
204 \pm 3.19 \\
225 \pm 1.19 \\
219 \pm 1.63 \\
223 \pm 1.30 \\
219 \pm 1.05 \\
223 \pm 0.80 \\
220 \pm 2.28\end{array}$ \\
\hline $\begin{array}{l}\text { CONT } \\
\text { cNaCl } \\
\text { cPYR } \\
\text { cKH }_{2} \mathrm{PO}_{4} \\
\text { cGLUC }\end{array}$ & $\begin{array}{l}117 \\
106 \\
117 \\
117 \\
117\end{array}$ & $\begin{array}{l}97.0 \\
85.6 \\
97.0 \\
97.0 \\
97.0\end{array}$ & $\begin{array}{l}7 \cdot 23 \\
7 \cdot 23 \\
7 \cdot 23 \\
5 \cdot 82 \\
7 \cdot 23\end{array}$ & $\begin{array}{l}1.41 \\
1.41 \\
1.41 \\
\overline{1.41}\end{array}$ & $\begin{array}{c}8.39 \\
8.39 \\
13.9 \\
8.39 \\
8.39\end{array}$ & $\begin{array}{l}7.6 \pm 0.13 \\
7.5 \pm 0.00 \\
7.5 \pm 0.03 \\
7.5 \pm 0.00 \\
7.5 \pm 0.00\end{array}$ & $\begin{array}{l}225 \pm 2.51 \\
204 \pm 3 \cdot 19 \\
224 \pm 1 \cdot 33 \\
219 \pm 1 \cdot 20 \\
219 \pm 1.76\end{array}$ \\
\hline
\end{tabular}

Phosphate, in the form of $\mathrm{KH}_{2} \mathrm{PO}_{4}$ or $\mathrm{Na}_{2} \mathrm{HPO}_{4}$, is present in almost all media used for culture and storage of mouse embryos. Our results indicate that the presence of phosphate is not essential in culture media that support mouse preimplantation development. In fact, reducing phosphate to 
a low level or removing it completely increased embryo development significantly. This finding contrasts with results obtained by Wales (1970), who determined that embryo development occurs within a wide range of phosphate concentrations and that only by removing phosphate completely will embryo development be reduced significantly. However, Schini \& Bavister (1988) have recently reported that phosphate at any concentration is detrimental to hamster embryo development.

Phosphate-buffered media have been used extensively to flush and wash embryos, because these media will maintain a steady $\mathrm{pH}$ in air. Investigators have even tried, with very limited success, to substitute phosphate for bicarbonate in culture medium so that embryos need not be cultured in a $5 \% \mathrm{CO}_{2}$ atmosphere (Quinn \& Wales, 1973; Mahadevan et al., 1986). In the present experiment, all embryos were flushed and washed in APBS, containing $6.75 \mathrm{~mm}$-phosphate, and remained in this medium for up to $2 \mathrm{~h}$ before transfer into culture medium. It is unknown, at this time, whether flushing embryos in a Hepes-buffered medium such as M2 (Quinn et al., 1982) and then culturing embryos in a medium such as $\mathrm{KKH}_{2} \mathrm{PO}_{4}$ might result in a higher rate of embryo development in vitro than we have reported at the present time.

Increasing the concentration of pyruvate in the medium from $0.42 \mathrm{~mm}$ (CONT) to $0.95 \mathrm{~mm}$ (hPYR) resulted in a decrease in the percentage of embryos which developed beyond the 2-cell stage and a decrease in the percentage of blastocysts (Fig. 3). There is previous evidence to suggest that pyruvate levels approaching $1 \mathrm{~mm}$ may be detrimental to embryo development (Brinster, 1965c), yet there is an absolute requirement for pyruvate for development in vitro of pronuclear-stage zygotes (Biggers et al., 1967). In the present experiment, when Medium hPYR resulted in reduced development, the simplex program generated Medium aPYR, with a reduced concentration of pyruvate. Embryo development in Medium aPYR improved considerably, compared to the CONT medium or hPYR.

Chatot et al. (1989) have reported that CF1 embryo development is reduced if glucose is present in the medium before the 4-cell or 8-cell stage, yet glucose is required for embryos to reach the blastocyst stage. During the course of the original simplex optimization experiments, we were surprised when Medium aGLUC, which has no glucose, supported development of zygotes into blastocysts. Therefore, we tested CZB medium, which also does not contain glucose. We found, in contrast to Chatot et al. (1989), that a high percentage of CF1 embryos will develop into blastocysts in CZB medium.

Our results demonstrate that a high percentage of embryos will grow in any of four media, $\mathrm{CZB}, \mathrm{aKH}_{2} \mathrm{PO}_{4}$, aPYR and aGLUC, which have very different compositions (Table 3). Two of these media have no glucose (CZB and aGLUC) and Medium $\mathrm{aKH}_{2} \mathrm{PO}_{4}$ has no phosphate, yet contains glucose. Medium aPYR contains both phosphate and glucose. Furthermore, the concentration of all of the other components is different in each of these media. The ability of embryos to grow under these various conditions suggests that there is no single optimum medium.

Increasing the concentration of one of three components, pyruvate, $\mathrm{NaCl}$ or $\mathrm{KH}_{2} \mathrm{PO}_{4}$, significantly decreased embryo development. Pyruvate concentration in Medium hPYR was significantly higher than the level measured in the oviduct (Gardner \& Leese, 1990; Table 5). Decreasing the concentration of pyruvate to a more physiological level (Media aPYR and cPYR) improved embryo development. Alternatively, $121 \mathrm{mM} \mathrm{NaCl}(\mathrm{hNaCl})$ will cause embryos to block at the 2-cell stage. The concentrations of $\mathrm{Na}^{+}$and $\mathrm{Cl}^{-}$in $\mathrm{M} 16$ and $\mathrm{hNaCl}$ (Table 4) are not very different from those found in the mouse oviduct (Roblero et al., 1976; Borland et al., 1977; Table 5). However, in the simplex-derived media which supported the development of a large percentage of embryos (aPYR, aKH ${ }_{2} \mathrm{PO}_{4}$ and aGLUC), the concentration of $\mathrm{Na}^{+}$and $\mathrm{Cl}^{-}$was much less than was found in the mouse oviduct. Furthermore, the osmolarity of these media (Table 4) is well below 300 mosmol, which is considered to be the physiological standard (Burton, 1975). Van Winkle et al. (1990) present evidence that the addition of glycine will promote embryo development in hyperosmotic media. Glycine may function as an osmolyte to regulate intracellular concentrations of inorganic ions (Somero, 1986). The absence of osmolytes and other components may have resulted in culture media with concentrations of inorganic ions that are vastly different from those found 
Table 5. Comparison of the concentrations (mM) of selected components and the osmolarity (mosmol) of Media $\mathrm{aKH}_{2} \mathrm{PO}_{4}, \mathrm{CZB}$ and $\mathrm{M} 16$ with ampullary fluid around the fertilized ova of the mouse

\begin{tabular}{lcccc}
\hline & \multicolumn{3}{c}{ Medium } & \\
\cline { 2 - 3 } Component & aKH ${ }_{2} \mathrm{PO}_{4}$ & $\mathrm{CZB}$ & $\mathrm{M} 16$ & $\begin{array}{c}\text { Oviduct } \\
\text { (ampula) }\end{array}$ \\
\hline $\mathrm{Na}^{+}$ & 114 & 138 & 143 & $139^{*}$ \\
$\mathrm{~K}^{+}$ & $6 \cdot 44$ & $6 \cdot 03$ & $5 \cdot 97$ & $29^{*}$ \\
$\mathrm{Cl}^{-}$ & $93 \cdot 8$ & $90 \cdot 3$ & 103 & $142^{*}$ \\
$\mathrm{PO}_{4}^{-}$ & 0 & $1 \cdot 17$ & $1 \cdot 19$ & $?$ \\
Lactate & $5 \cdot 1$ & $30 \cdot 1$ & $23 \cdot 3$ & $4 \cdot 79 \dagger$ \\
Pyruvate & 0.38 & $0 \cdot 26$ & $0 \cdot 33$ & $0 \cdot 37 \dagger$ \\
Glucose & 1.54 & 0 & $5 \cdot 56$ & $3 \cdot 40 \dagger$ \\
Glutamine & $1 \cdot 72$ & $1 \cdot 0$ & 0 & $0 \cdot 20 \dagger$ \\
Observed & & & & \\
osmolarity & 219 & 259 & 271 & $?$ \\
2-cell block & - & - & + & $?$ \\
(CF1) & & & & \\
\hline
\end{tabular}

*Borland et al. (1977).

†Gardner \& Leese (1990).

in vivo. The components of the culture media that we have developed represent only a small proportion of the substances which comprise the complex milieu of the mouse oviduct. We may need to re-examine our definition of what is physiological when discussing development in vitro, as our results indicate that the in-vivo concentrations of certain components may actually be detrimental, under certain conditions, for embryo development in vitro.

The simplex-derived media reported in this paper are from the initial stages of the procedure. The actual optimization process has not been completed and it is possible that future media may be even better than those developed at this time. Although we have applied this method for developing culture media, simplex optimization could be used to improve the in-vitro conditions of any number of biological systems.

We thank Dr Barry Bavister, Dr Robert Foote and Dr Betsey Williams for critically reviewing the manuscript; and Ms Carol Kountz for proof reading. This work was part of the National Cooperative Program on Non-Human In Vitro Fertilization and Preimplantation Development, grant HD21988. Animals used in this study were maintained in accordance with the guidelines of the Committee on Animals of the Harvard Medical School and those prepared by the Committee of Care and Use of Laboratory Animals of the Institute of Laboratory Animal Resources, National Research Council (DHHS Publication No. (NIH) 85-23, revised 1985).

\section{References}

Baltz, J.M., Biggers, J.D. \& Lechene, C. (1990) Apparent absence of $\mathrm{Na}^{+} / \mathrm{H}^{+}$antiport activity in the two-cell mouse embryo. Devl Biol. 138, 421-429.

Baltz, J.M., Biggers, J.D. \& Lechene C. (1991) Two-cellstage mouse embryos appear to lack mechanisms for alleviating intracellular acid loads. J. Biol. Chem. (In Press).

Biggers, J.D., Rinaldini, L.M. \& Webb, M. (1957) The study of growth factors in tissue culture. Symp. Soc. exp. Biol. 11, 264-297.
Biggers, J.D., Whittingham, D.G. \& Donahue, R.P. (1967) The pattern of energy metabolism in the mouse oocyte and zygote. Proc. natn. Acad. Sci. USA 58, $560-567$.

Biggers, J.D., Whitten, W.K. \& Whittingham, D.G. (1971) The culture of mouse embryos in vitro. In Methods of Mammalian Embryology, pp. 7-21. Ed. J. C. Daniel. Freeman, San Francisco.

Borland, R.M., Hazra, S., Biggers, J.D. \& Lechene, C.P. (1977) The elemental composition of the environments 
of the gametes and preimplantation embryo during the initiation of pregnancy. Biol. Reprod. 16, 147-157.

Brinster, R.L. (1965a) Studies on the development of mouse embryos in vitro. IV. Interactions of energy sources. J. Reprod. Fert. 10, 227-240.

Brinster, R.L. (1965b) Studies on the development of mouse embryos in vitro. I. The effect of osmolarity and hydrogen ion concentration. J. exp. Zool. 158, 49-58.

Brinster, R.L. (1965c) Studies on the development of mouse embryos in vitro. II. The effect of energy source. J. exp. Zool. 158, 59-68.

Burton, R.F. (1975) Ringer Solutions and Physiological Salines, p. 61. Wright Scientechnica, Bristol.

Chatot, C.L., Ziomek, C.A., Bavister, B.D., Lewis, J.L. \& Torres, I. (1989) An improved culture medium supports development of random-bred 1-cell mouse embryos in vitro. J. Reprod. Fert. 86, 679-688.

Chatot, C.L., Lewis, J.L., Torres, I. \& Ziomek, C.A. (1990) Development of 1-cell embryos from different strains of mice in CZB medium. Biol. Reprod. 42, 432-440.

Cole, R.J. \& Paul, J. (1965) Properties of cultured preimplantation mouse and rabbit embryos, and cell strains derived from them. In Preimplantation Stages of Pregnancy, pp. 82-122. Eds G. E. W. Wolstenholme \& M. O'Connor. Churchill, London.

Cox, D.R. (1958) Planning of Experiments, p. 252. Wiley, New York.

Cross, P.C. \& Brinster, R.L. (1973) The sensitivity of one-cell mouse embryos to pyruvate and lactate. Expl Cell Res. 77, 57-62.

Dandekar, P.V. \& Glass, R.H. (1987) Development of mouse embryos in vitro is affected by strain and culture medium. Gamete Res. 17, 279-285.

Deming, S.N. \& Morgan, S.L. (1973) Simplex optimization of variables in analytical chemistry. Analyt. Chem. 45, 278a-283a.

Ebert, K.M. \& Brinster, R.L. (1983) Rabbit $\alpha$-globin messenger RNA translation by the mouse ovum. $J$. Embryol. exp. Morph. 74, 159-168.

Gardner, D.K., Clarke, R.N., Lechene, C.P. \& Biggers, J.D. (1989) Development of a noninvasive ultramicrofluorometric method for measuring net uptake of glutamine by single preimplantation mouse embryos. Gamete Res. 24, 427-438.

Gardner, D.K. \& Leese, H.J. (1990) Concentrations of nutrients in mouse oviduct fluid and their effects on embryo development and metabolism in vitro. $J$. Reprod. Fert. 88, 361-368.

Hogan, B., Costantini, F. \& Lacy, E. (1986) In vitro culture of eggs, embryos, and teratocarcinoma cells. In Manipulating the Mouse Embryo, p. 255. Cold Spring Harbor Laboratory, New York.

Laubscher, N.F. (1961) On stabilizing the binomial and negative binomial variances. $J$. Am. statist. Assoc. 56, $143-150$.

Loutradis, D., John, D. \& Kiessling, A.A. (1987) Hypoxanthine causes a 2-cell block in random-bred mouse embryos. Biol. Reprod. 37, 311-316.

Mahadevan, M.M., Fleetham, J., Church, R.B. \& Taylor, P.J. (1986) Growth of mouse embryos in bicarbonate media buffered by carbon dioxide, hepes, or phosphate. J. In Vitro Fert. Emb. Transfer 3, 304-308.
Muggleton-Harris, A. \& Brown, J.J.G. (1988) Cytoplasmic factors influence mitochondrial reorganization and resumption of cleavage during culture of early mouse embryos. Human Reprod. 3, 1020-1028.

Muggleton-Harris, A., Whittingham, D.G. \& Wilson, L. (1982) Cytoplasmic control of preimplantation development in vitro in the mouse. Nature, Lond. 229, $460-462$.

Pomp, D., Critser, E.S. \& Rutledge, J.J. (1988) Lower sodium lactate in Whitten's medium improves in vitro developmental capacity of one-cell mouse embryos. Theriogenology 29, 1019-1025.

Quinn, P. \& Wales, R.G. (1973) Growth and metabolism of preimplantation mouse embryos cultured in phosphate-buffered medium. J. Reprod. Fert. 35, 289-300.

Quinn, P., Barros, C. \& Whittingham, D.G. (1982) Preservation of hamster oocytes to assay the fertilizing capacity of human spermatozoa. J. Reprod. Fert. 66, 161-168.

Roblero, L., Biggers, J.D. \& Lechene, C.P. (1976) Electron probe analysis of the elemental microenvironment of oviducal mouse embryos. J. Reprod. Fert. 46, 431-434.

Routh, M.W., Swartz, P.A. \& Denton, M.B. (1977) Performance of the super modified simplex. Analyt. Chem. 49, 1422-1428.

Schini, S.A. \& Bavister, B.D. (1988) Two-cell block to development of cultured hamster embryos is caused by phosphate and glucose. Biol. Reprod. 39, 1183-1192.

Somero, G.N. (1986) Protons, osmolytes, and fitness of internal milieu for protein function. Am. J. Physiol. 251, R197-R213.

Spendley, W., Hext, G.R. \& Himsworth, F.R. (1962) Sequential application of simplex designs in optimisation and evolutionary operation. Technometrics $\mathbf{4}$, $441-461$.

Spindle, A. (1990) In vitro development of one-cell embryos from outbred mice: influence of culture medium composition. In Vitro Cell. Dev. Biol. 25, 151-156.

van der Wiel, P.F.A. (1980) Improvement of the supermodified simplex optimization procedure. Analyt. Chim. Acta 122, 421-433.

van der Wiel, P.F.A., Vaassen, R. \& Kateman, G. (1983) The symmetry-controlled simplex optimization procedure. Analyt. Chim. Acta 153, 83-92.

Van Winkle, L.J., Haghighat, N. \& Campione, A.L. (1990) Glycine protects preimplantation mouse conceptuses from a detrimental effect on development of the inorganic ions in oviductal fluid. J. exp. Zool. 253, 215-219.

Wales, R.G. (1970) Effects of ions on the development of the preimplantation mouse embryo in vitro. Aust. $J$. biol. Sci. 23, 421 .

Whitten, W.K. \& Biggers, J.D. (1968) Complete development in vitro of the preimplantation stages of the mouse in a simple chemically defined medium. $J$. Reprod. Fert. 17, 399-401.

Whittingham, D.G. (1971) Culture of mouse ova. $J$. Reprod. Fert., Suppl. 14, 7-21.

Whittingham, D.G. \& Biggers, J.D. (1967) Fallopian tube and early cleavage in the mouse. Nature, Lond. 213, 942-943. 